\title{
Long-Term Performance of Trestle Bridges: Case Study of an Indonesian Marine Port Structure
}

\author{
Yusak Oktavianus ${ }^{1}$, Massoud Sofi ${ }^{1, *(1)}$, Elisa Lumantarna ${ }^{1}$, Gideon Kusuma ${ }^{2}$ and \\ Colin Duffield ${ }^{1}$ \\ 1 Department of Infrastructure Engineering, The University of Melbourne, Parkville 3010, Australia; \\ Yusak.oktavianus@unimelb.edu.au (Y.O.); elu@unimelb.edu.au (E.L.); colinfd@unimelb.edu.au (C.D.) \\ 2 Everbest G \& I, 33 Sherwood road, Mount Waverley, VI 3149, Australia; gideonkusuma@drhme.com.au \\ * Correspondence: massoud@unimelb.edu.au; Tel.: +61-4513-318-62
}

Received: 1 April 2020; Accepted: 14 May 2020; Published: 19 May 2020

\begin{abstract}
A precast reinforced concrete (RC) T-beam located in seaport Terminal Peti Kemas (TPS) Surabaya built in 1984 is used as a case study to test the accuracy of non-destructive test techniques against more traditional bridge evaluation tools. This bridge is mainly used to connect the berth in Lamong gulf and the port in Java Island for the logistic purposes. The bridge was retrofitted 26 years into its life by adding two strips of carbon fiber reinforced polymer (CFRP) due to excessive cracks observed in the beams. Non-destructive field measurements were compared against a detailed finite element analysis of the structure to predict the performance of the girder in terms of deflection and moment capacity before and after the retrofitting work. The analysis was also used to predict the long-term deflections of the structure due to creep, crack distribution, and the ultimate moment capacity of the individual girder. Moreover, the finite element analysis was used to predict the deflection behavior of the overall bridge due to vehicle loading. Good agreement was obtained between the field measurement and the analytical study. A new service life of the structure considering the corrosion and new vehicle demand is carried out based on field measurement using non-destructive testing. Not only are the specific results beneficial for the Indonesian port authority as the stakeholder to manage this structure, but the approach detailed also paves the way for more efficient evaluation of bridges more generally over their service life.
\end{abstract}

Keywords: seaport; bridge; durability; FEM; crack

\section{Introduction}

Indonesia is a tropical country that consists of more than 17000 islands. The wet, hot, humid climate aggressively deteriorates bridges. This is particularly true for seaports, (a critical part of Indonesia's infrastructure) and both the provision of new infrastructure and retrofitting aging assets has consumed greater than 5\% of the country's gross domestic product (GDP) [1]. Based on the data obtained from Directorate General Bina Marga [2], the total road network in Indonesia is $488,181 \mathrm{~km}$ in 2015. Moreover, it is expected that there will be a new road of 15,000 km in 2019 to support tourism, airports, seaports, and railways. In addition to building new infrastructure, it is also stated that there is approximately $47,000 \mathrm{~km}$ of roads and $446 \mathrm{~km}$ of the bridge that is needed to be retrofitted.

In addition to the high maintenance costs, there have been one to two major bridges collapse every year for each of the last eight years in Indonesia. For instance, Tenggarong bridge in Kutai on 2011, Cidua bridge in Bogor on 2012, Bangbayang bridge in Garut on 2014, Serang bridge in Banten on 2014, Lebak bridge in Banten on 2015, Bengkulu bridge in Bengkulu on 2016, Klungkung bridge in Bali on 2016, Tanipah bridge in South Kalimantan on 2017, Widang bridge in East Java on 2018 [3-5]. 
These bridges include reasonably newly built structures, recently retrofitted facilities, and old bridges that have served their service life.

High bridge maintenance costs are not unique to Indonesia, e.g., existing infrastructure in Australia is requiring substantial additional funding for maintenance, renewal, and upgrade with growing population. Australian bridges that were built decades ago are now subject to an additional load of about 5.6\% annually. The annual maintenance expense for the 33,500 bridges in Australia is around $\$ 100$ million, and the replacement cost of deficient bridges is estimated to run into billions of dollars [6].

Degradation of concrete bridges happens due to overweight vehicles, corrosion of the reinforcement, increasing volume of traffic, and natural events such as earthquakes and tsunamis. Periodical assessment is therefore required to predict the service life prediction of the bridges. The main reasons for the collapse of the bridges are the overweight vehicle, corrosion, and inadequate maintenance practices. These are some of the new challenges to overcome when designing reinforced concrete (RC) bridges. Excessive cracking and displacement under service load and even failure of structure can happen as a result of the time-dependent reduction in strength and stiffness of concrete.

Creep, shrinkage, and relaxation can increase the deflection of the structure significantly over time. Extensive research in this area has been conducted since the 1970s. This includes experimental work on the effect of creep (time-dependent deformation) to the crack of the plain concrete [7] and high strength concrete [8]. The American Association of State Highway and Transportation Officials (AASHTO) [9] included creep, shrinkage, and relaxation to obtain the total deformation of the member. Moreover, flexural creep tests were conducted on partially damaged concrete specimens [9] and beams of various sizes [10]. The inclusion of creep in the deflection calculation is crucial since the time-dependent deformation can induce microcracks. Hence, it will reduce the capacity and the service life of the structure.

Sea freight is the dominant means to deliver the goods internationally, and this is particularly true in Indonesia since it consists of thousands of islands, local sea freight has taken up to $90 \%$ of the local goods distribution. Seaports are critical to the Indonesian economy any downtime due to failure of critical infrastructure would cause significant economic loss. Moreover, once a seaport is damaged, it will usually take a long time to restore [11]. For instance, the 1995 Kobe earthquake severely damaged numerous ports, and it caused long-term economic loss in Japan. Moreover, the closure of the ports in Haiti [12] and Andaman [13] caused access difficulty in delivering relief supplies.

Liquefaction and poor soil conditions are the main external factors affecting the seismic performance of the seaport's structures. Moreover, substandard design and lack of routine maintenance are also other main factors affecting the structures' performance of the seaports. When subjected to earthquakes or other unlikely events, these structures can be more at risk of collapse. For instance, the corrosion of the steel reinforcement, poor detailing, and deficient shear reinforcement become the main factors causing the damages of the structures supporting piles during the 2004 Sumatra earthquake in Andaman Islands [13].

The main cause of deterioration in structural concrete exposed to the marine environment is the chloride penetration in the concrete. This phenomenon is strongly contingent on properties of concrete such as water content and porosity of the concrete cover. When conducting structural health assessment and durability diagnosis, non-destructive testing (NDT) of concrete cover provides important information about the condition of the concrete and is an indicator of durability. The authors have previously suggested a hybrid use of different types of NDT equipment in assessing in situ concrete such as that for concrete cover measurement and locating the arrangement of the reinforcements, air permeability, electrical resistivity and the half-cell potential [14].

The existing condition of ports structures located in Indonesia has been subject of recent investigation. Several RC bridges of a high level of importance were investigated such that different exposure conditions and ages of structures could be investigated. This research specifically focused on the effect of corrosion and overweight loads on the bridge structural elements. 
This paper presents the analysis of the precast reinforced concrete $(\mathrm{RC})$ bridge located in Terminal Peti Kemas (TPS) Surabaya (Indonesia). The bridge connects the berth and the port with the hinterland and is a critical element for the transport of goods. Nine T-beams were integrated into a monolithic structure through a cast concrete slab on top of the beams. The resulting monolithic behavior increases the stiffness and capacity of the bridge over the simple sum of restraint provided by the T-beams, especially for point loads. Frequently bridge investigations do not fully consider the group effects when predicting deflections since the loading is assumed to be uniformly distributed. Effectively the analysis reverts to that of a single T-beam instead of the integrated analysis of a group of beams $[15,16]$. This study considers such group effects and has considered specific axle loads as well as the uniformly distributed such as self-weight. Influence lines were used to obtain the location of the maximum deflection and moment subjected to a moving truck.

The bridge was surveyed at two stages. The first stage involved field measurements performed 26 years after its construction and measured deflections prior to and after retrofitting works were undertaken. The company conducting the retrofitting works conducted the field survey to obtain the deflection. The second stage involved the use of NDT performed when the structure was 34 years old. This investigation focused on the initiation and propagation of cracks and corrosion [17]. The NDT testing was conducted to determine the carbonation rate which combined with deflection data allows estimation of the service life of the structure. Four types of NDT equipment were used, and measurements were taken to obtain the concrete cover, concrete compressive strength, air permeability (related to carbonation rate and initiation time of corrosion) and electrical resistivity (related to corrosion rate or propagation time). Additional details of the NDT and results have been previously reported by the authors [17]. Both carbonation and corrosion propagation rate were defined as a basis for determination of the total service life of the beams.

This research uses fiber element analysis to predict the behavior of the beam due to self-weight only. Moreover, finite element analysis is used to predict the deflection of a group of parallel beams under self-weight and wheel loading. Influence lines are incorporated into the finite element analysis to determine critical wheel-load patterns. Initially, the analytical results were compared to those obtained from the field measurements and then the model was extended to understand the influence of the addition of carbon fiber reinforced polymer (CFRP) layers used in the retrofitting works. Fiber element analysis is used to predict the non-linear behavior of RC sections $[18,19]$. The RC sections are divided into several discretized element and the behavior of each element is evaluated according to the predefined stress-strain relationship of each type of material This provided information on the levels of corrosion, and influence of specific vehicular loads on the behavior of the beam. Ultimately, the total service life of the bridge was estimated by using the additional information obtained from the NDT. This information is very useful for the stakeholder to make a strategic decision to maintain the performance of the bridge over its service life.

\section{Case Study}

The RC trestle bridge at Terminal Peti Kemas (TPS) in the seaport of Tanjung Perak, Surabaya, Indonesia, is mainly used by trucks to transport the containers to and from the berth. The Port of Tanjung Perak is the busiest port in Indonesia. Hence, the failure of this bridge should be prevented to avoid a significant economic loss to the country due to the downtime period. Figure 1 depicts the view of the RC bridge in TPS from the domestic harbor. The bridge consists of 100 spans with a length of $15 \mathrm{~m}$ for each span [20]. Each span is simply sitting on an RC cross beam through a rubber bearing. Ultimately, the cross beam is supported by three circular steel piles which are protected with anti-corrosion wrap. Figure 2 depicts the typical cross-section of the bridge, including the details of the RC deck beam (adapted from BGA [21]). 


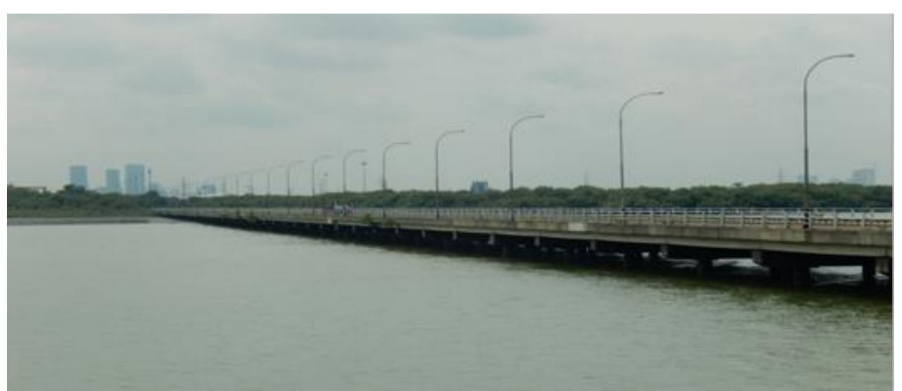

Figure 1. The view of the RC bridge in TPS (from the domestic harbor).

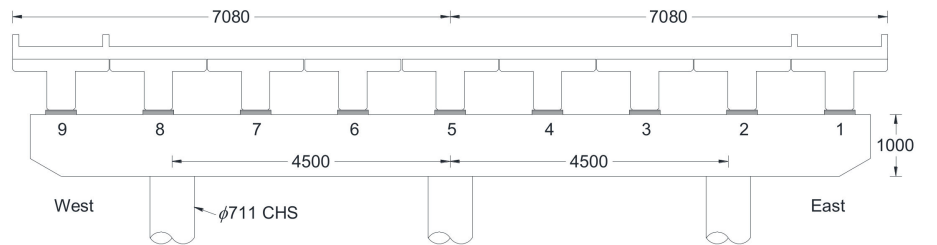

(a)

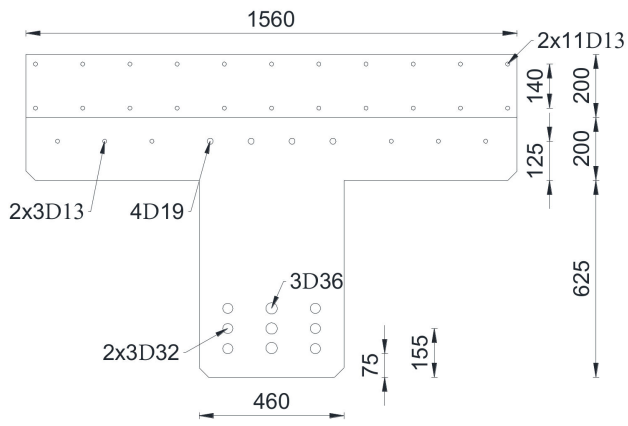

(b)

Figure 2. Typical RC bridge in TPS: (a) Cross-section of the bridge looking to the harbor; (b) The details for one RC deck beam.

From the as-built-drawings, a design compressive strength of $40 \mathrm{MPa}$ was obtained for the concrete. The yield and ultimate strength of 400 and $500 \mathrm{MPa}$ for the main rebar and 250 and $320 \mathrm{MPa}$ for the stirrups were also obtained from the as-built-drawing. The bridge is approximately 26 years old at the time of the first inspection in 2010. The cracking moment capacity of the cross-section of one T-beam is approximately equal to $400 \mathrm{kNm}$. However, the self-weight of the T-beam itself generates a moment of approximately $640 \mathrm{kNm}$. Moreover, a maximum truckload of approximately 48 tons distributed to two front wheels and two back wheels were used to observe the additional deflection of the beam. The distance between the front and the back wheels is approximately equal to $10 \mathrm{~m}$. Hence, to simulate the worst-case scenario, either front wheel or back wheel will be positioned in the middle of the span. It will be equivalent to approximately $118 \mathrm{kN}$ point load for each wheel with a track distance of $1.8 \mathrm{~m}$, as shown in Figure 7. The service load $(\mathrm{G}+1.15 \mathrm{Q})$ exceeded the cracking moment capacity, and hence a lot of cracks were observed before the retrofitting work in 2010, as shown in Figure 3. Further work was accomplished in Section 3 to observe the group effect of the beams.

The T-beam was repaired in 2010 by grouting the cracks to protect the steel reinforcement from direct contact with the environment, which can cause corrosion. In addition, two strips of CFRPs Sika CarboDur type S10-12 was added along the bottom of the T-beam [21]. One strip of CFRP has a width and a thickness of 100 and $1.2 \mathrm{~mm}$, respectively. Therefore, the total cross-sectional area for two carbon fiber strips is equal to $240 \mathrm{~mm}^{2}$. Moreover, it has a tensile strength of $2800 \mathrm{MPa}$ and Young's modulus of $165,000 \mathrm{MPa}$. 


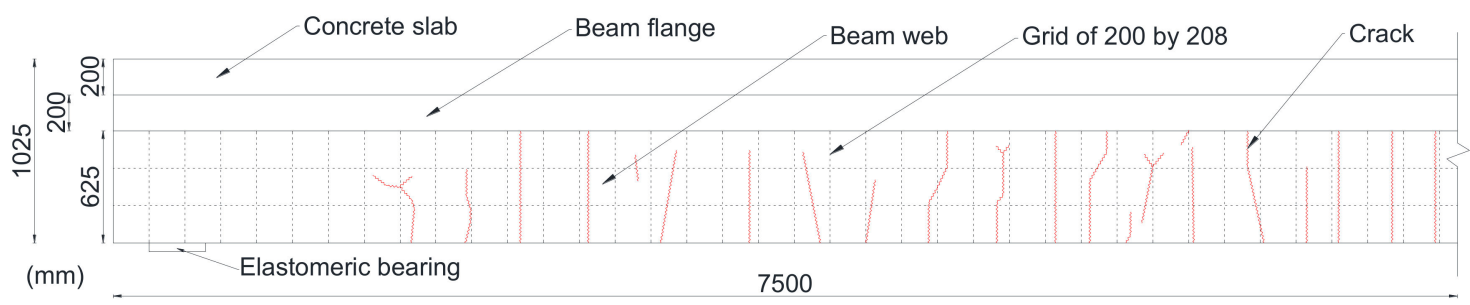

Figure 3. Crack distribution on the T-beam (half beam) prior to the retrofitting work on 2010.

\section{Fiber Element Analysis and Finite Element Analysis}

Both fiber element analysis and finite element analysis were performed to observe the behavior of the cross-section of individual T-beam and the group behavior of the T-beam, respectively. Response 2000 developed in the University of Toronto [22] was used to perform the fiber element analysis of the cross-section of individual T-beam due to the self-weight. In this case, there is no group effect since the self-weight of the beam is uniformly distributed throughout the slab. Figure 4a shows the input used to model the RC T-beam using Response 2000 following the details shown in Figure $2 \mathrm{~b}$. In case of the beam that is reinforced with CFRP, an additional steel reinforcement at the bottom of the beam with an area of $240 \mathrm{~mm}^{2}$ was added as shown in Figure $4 \mathrm{~b}$. The stress-strain relationship of the concrete under compression was modelled using the modified base curve proposed by Popovics and Collins [23,24]. The compression stiffening for RC subjected to shear was modelled based on the work done by Vecchio and Collins [25]. Moreover, the tension stiffening of the concrete was modelled following Bentz [22] to consider the tensile resistance of cracked concrete. The concrete compressive strength obtained from the NDT measurement was used instead of using the value obtained from the as-built-drawing. This is equal to 51 and 7.6 MPa for the mean and the standard deviation of the concrete compressive strength. However, the yield and ultimate strength of the reinforcement (both for stirrups and the main rebar) still follow the value stated in the as-built-drawing due to limited information. The stress-strain relationship for the steel follows the default model suggested in Response 2000 by assuming the strain at strain-hardening and at rupture of $2 \mathrm{~mm} / \mathrm{m}$ and $100 \mathrm{~mm} / \mathrm{m}$, respectively. For the CFRP, strain at strain-hardening and rupture of $17 \mathrm{~mm} / \mathrm{m}$ and $35 \mathrm{~mm} / \mathrm{m}$, respectively, were used. This model can capture the elastic, post-yield plastic, and strain-hardening behavior of the steel.

As mentioned previously, when time-dependent deflection was considered, the creep and shrinkage model suggested by AASHTO [9] was incorporated. Figure 5 shows the crack distribution along the beam prior to the retrofitting work due to only the self-weight, which agrees well with the field observation shown in Figure 3. The figure displays the difference of the crack distribution and deflection between the newly built and the 26-year old bridge. Figure 6 shows that the deflection predicted by Response 2000 also agrees well with the field measurement on two different beams with an error of 1 and 10\% for Beam 6 and Beam 3, respectively. Please note that there were only two beams (beam 6 and beam 3) used in the field test. The result shows that AASHTO [9] model was reasonably accurate and conservative to be used to include the effect of the creep, shrinkage, and relaxation. Moreover, it is also shown in Figure 6 that by taking the creep for 26 years into account, it will increase the maximum midspan displacement due to self-weight to approximately 2.3 times of the immediate deflection. 


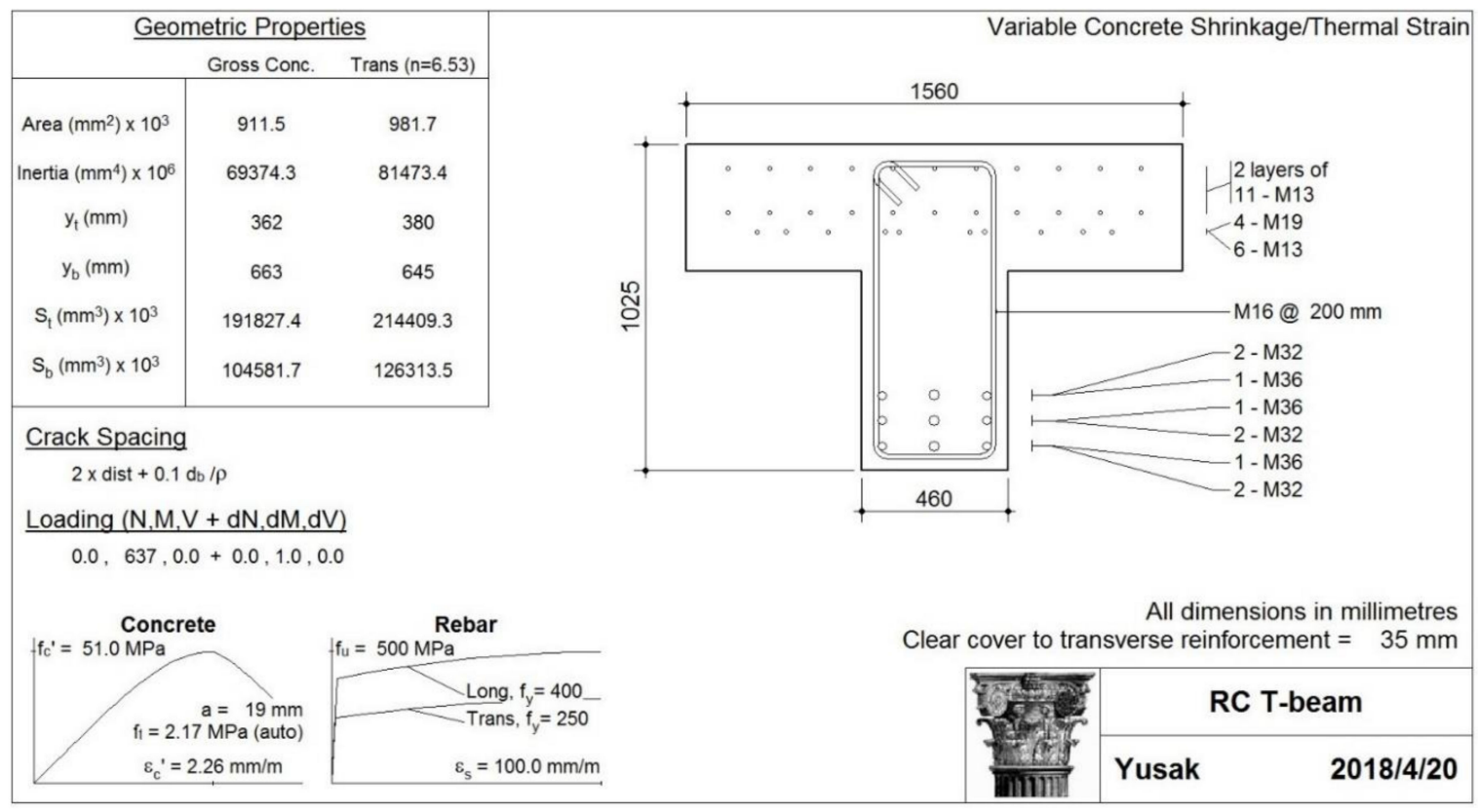

(a)

\begin{tabular}{|c|c|c|c|}
\hline \multicolumn{3}{|c|}{ Geometric Properties } & \\
\hline \multicolumn{2}{|r|}{ Gross Conc. } & Trans $(n=6.59)$ & \\
\hline Area $\left(\mathrm{mm}^{2}\right) \times 10^{3}$ & 911.5 & 947.4 & \\
\hline Inertia $\left(\mathrm{mm}^{4}\right) \times 10^{6}$ & 69374.3 & 75874.4 & \\
\hline$y_{t}(m m)$ & 362 & 372 & \\
\hline$y_{b}(m m)$ & 663 & 653 & \\
\hline $\mathrm{S}_{\mathrm{t}}\left(\mathrm{mm}^{3}\right) \times 10^{3}$ & 191827.4 & 204145.5 & \\
\hline $\mathrm{S}_{\mathrm{b}}\left(\mathrm{mm}^{3}\right) \times 10^{3}$ & 104581.7 & 116134.6 & \\
\hline \multicolumn{4}{|l|}{ Crack Spacing } \\
\hline \multicolumn{4}{|c|}{$2 \times$ dist $+0.1 \mathrm{db} / \rho$} \\
\hline \multicolumn{4}{|c|}{ Loading $(N, M, V+d N, d M, d V)$} \\
\hline \multicolumn{4}{|c|}{$0.0,-0.0,0.0+0.0,1.0,0.0$} \\
\hline \multicolumn{2}{|c|}{$f_{\mathrm{f}^{\prime}}=49.8 \mathrm{MPa}$} & $=2850 \mathrm{MPa}$ & $\begin{array}{l}\text { Ir } \\
\text { RP, } f_{y}=2800 \\
\text { ong, } f_{y}=400 \\
\text { ans, } f_{y}=250\end{array}$ \\
\hline & $4 \mathrm{~mm} / \mathrm{m}$ & & $=100.0 \mathrm{~mm} / \mathrm{m}$ \\
\hline
\end{tabular}

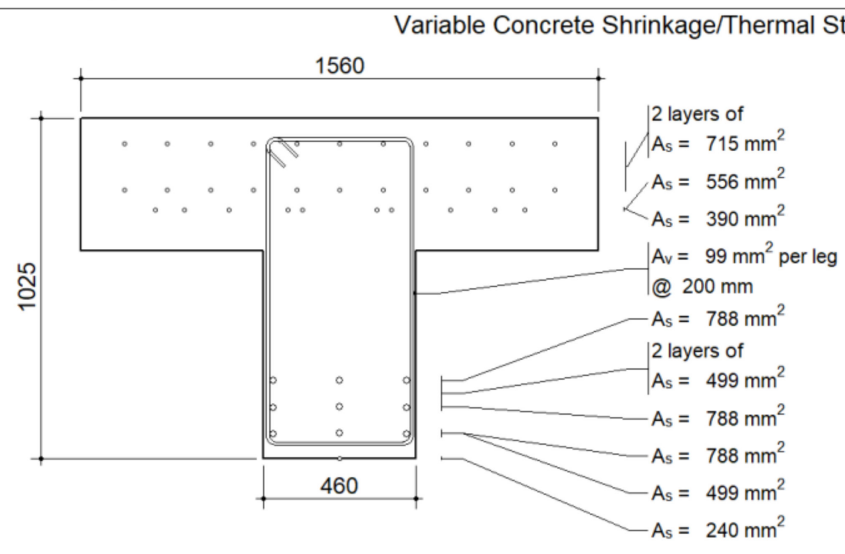

All dimensions in millimetres Clear cover to reinforcement $=7 \mathrm{~mm}$

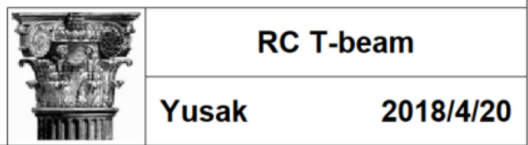

(b)

Figure 4. Input for the section analysis using Response 2000: (a) without CFRP; (b) with CFRP.
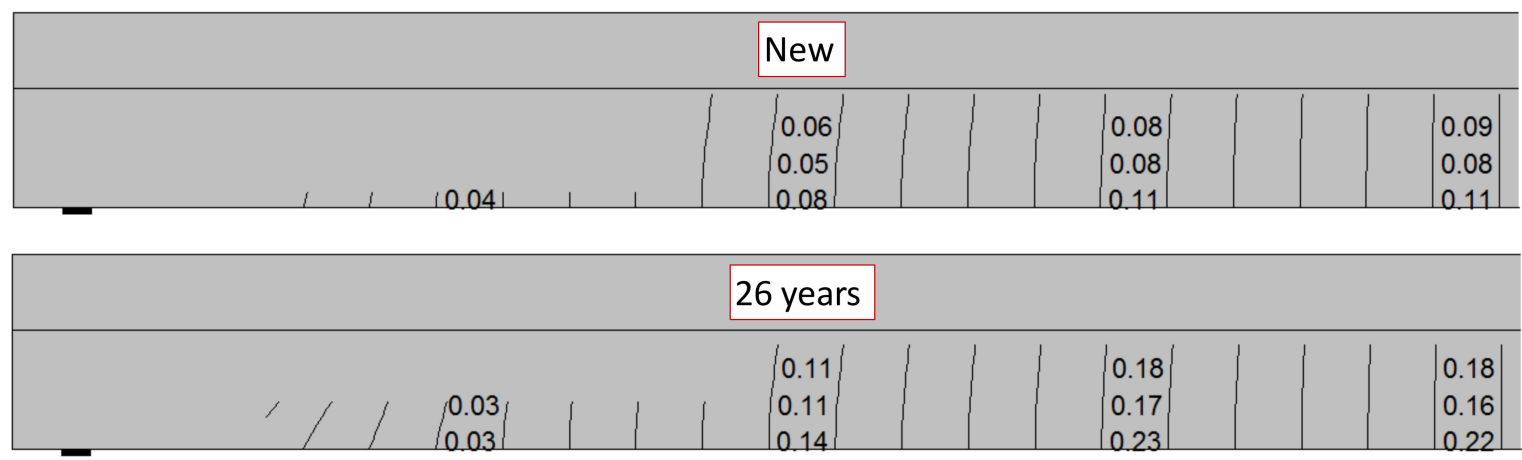

Figure 5. The crack distribution obtained from Response 2000. 


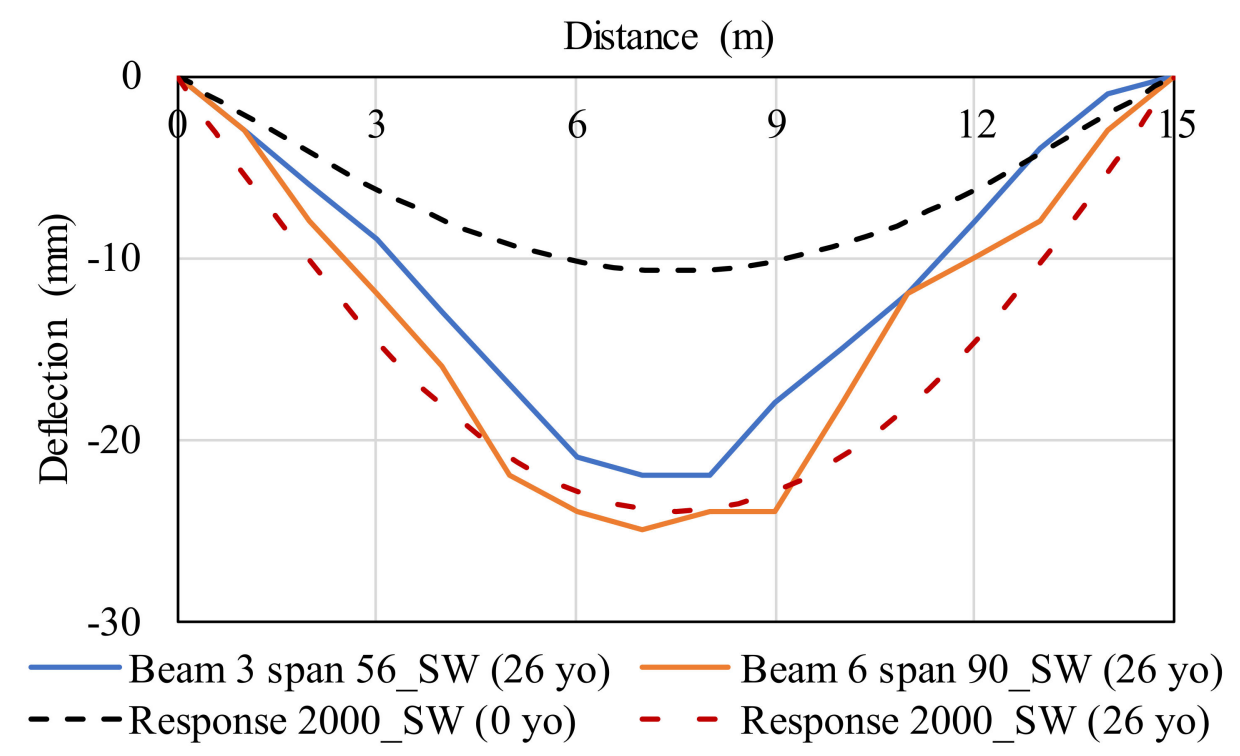

Figure 6. The deflection of the beam obtained from both field measurement and Response 2000.

From the influence line theory, it is expected that the maximum bending moment and deflection of a simply supported beam will occur at the midspan due to the moving load either from the front or back wheel of the truck. Since the bridge provides two-way access, the worst case will be from two pairs of wheel load from the trucks when they are passing each other. However, during the field measurement, there is only one truck passing the observed span each time, and therefore, only one pair of wheel load will be acting in the middle of the span. In this case, analysis of a group of T-beams instead of the individual beam was performed, since the beam will act together as a group to carry the wheel loading from the truck. This was achieved by modelling a group of nine T-beams in one span using finite element software ETABS v13.2.2 [26] as shown in Figure 7 which shows that the bridge is subjected to front wheel loading of $2 \times 118.21 \mathrm{kN}$ (1.8 $\mathrm{m}$ apart) along the midspan. The back wheel was not modelled since it was acting on top of the adjacent span. As mentioned previously, and influence line analysis in the transverse direction was performed to obtain the most critical location of the wheel, which generates the maximum bending moment of the observed beam. The observed beam is beam number 4 from the left (refer to Figure 7) or beam number 6 (refer to Figure 2a) in span 90. From the finite element analysis (FEA), the most critical location of the wheel, which will generate the highest bending moment at beam 6, will be at $3.15 \mathrm{~m}$ and $4.95 \mathrm{~m}$ from the center of Beam 9 (refer to Figure 2a). With a good match of the deflection due to the self-weight of the beam between the field measurement and Response 2000, the material properties of individual T-beam obtained from Response 2000 (such as the unit weight of the RC beam and slab and the effective flexural stiffness, $E I_{e f f}$ ) were used in the group analysis. This was accomplished to represent the actual behavior of the beam.

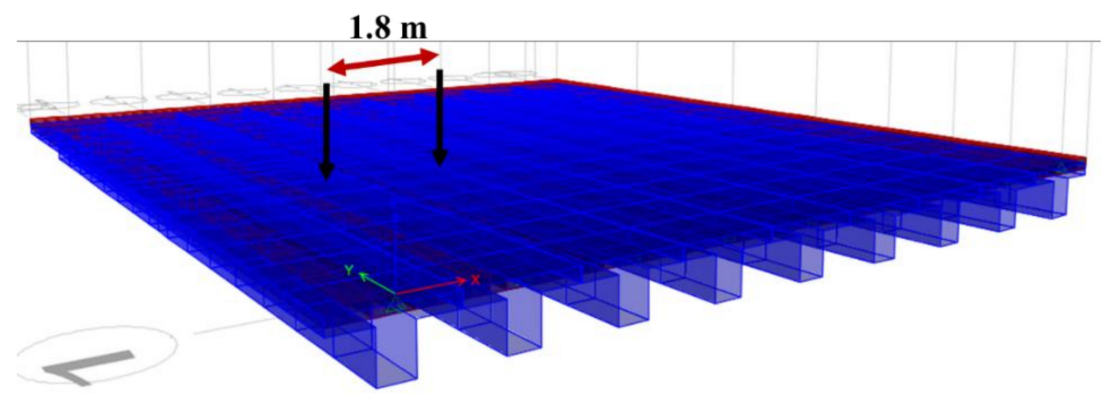

Figure 7. Finite element modelling of a group of nine T-beams. 
Figure 8 shows the comparison between the deflection obtained from the field measurement and that obtained from finite element analysis package ETABS v13.2.2 by using the material properties obtained from RESPONSE 2000. It is shown that the result obtained from the FEA agrees well with those obtained from the field measurement. The additional moment due to the front wheel load at the critical location is approximately equal to only $200 \mathrm{kNm}$. This value is approximately equal to $46 \%$ of the maximum moment generated at the midspan of individual T-beam subjected to a one-point load of $118 \mathrm{kN}$. It means that the group effect can reduce the maximum moment due to the wheel up to $54 \%$ compared with the case of individual T-beam. It is shown in Figure 8 that the maximum deflection due to the combined long-term self-weight and the wheel load is approximately equal to $27 \mathrm{~mm}$ from the analytical approach and $28 \mathrm{~mm}$ from the field measurement. This maximum deflection at service is still less than the limit of the span on 480 , which is equal to $31 \mathrm{~mm}$. The discrepancy observed in deflection of Beam 6 is expected. It can be traced back to error sourced from the measuring devices, and, possibly the exact location where the deflection is measured is slightly off.

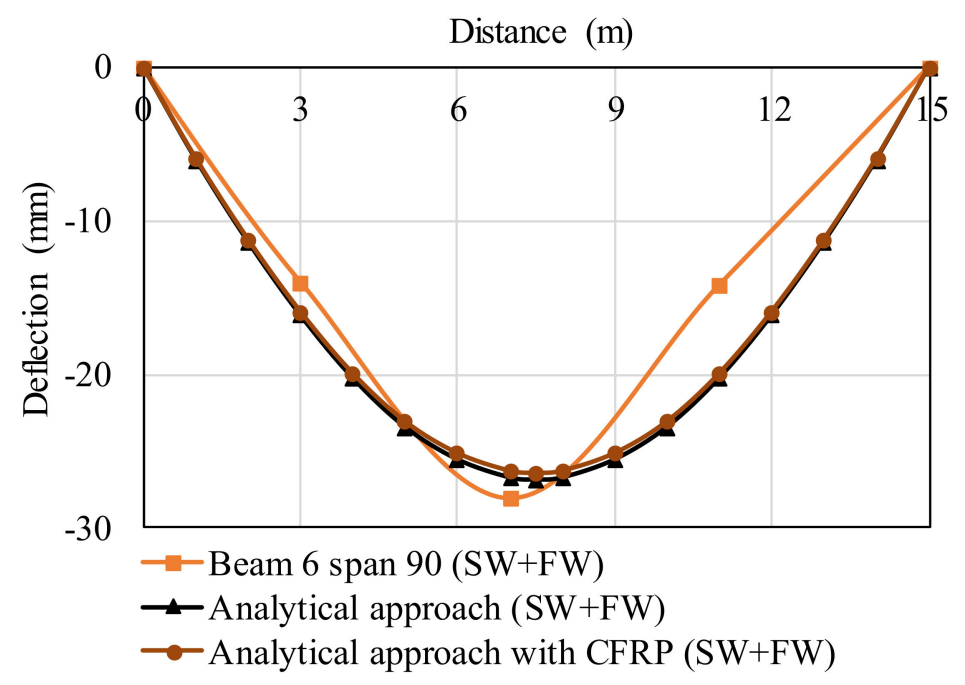

Figure 8. The deflection of the beam obtained from both field measurement and ETABS v13.2.2.

\section{The Effect of Adding Two Strips of CFRP}

The T-beam has been repaired in 2010 by grouting the cracks to maintain the thickness of the concrete cover. In addition, two strips of CFRP Sika CarboDur type S10-12 was added along the bottom of the T-beam [21]. Figure 9a shows the section moment capacity of individual T-beam with and without the inclusion of CFRP. It is shown that by adding two strips of CFRP, the ultimate moment capacity of the beam increases by $14 \%$ from approximately $3300 \mathrm{kNm}$ to $3770 \mathrm{kNm}$. By adding CFRP, the yield capacity of the beam also increases by $11 \%$ from approximately $2590 \mathrm{kNm}$ to $2867 \mathrm{kNm}$. However, the initial stiffness of the beam is similar between the beam with or without CFRP. It means that the deflection of the beam remains similar no matter CFRP is added or not to the beam. Once the CFRP reaches its ultimate capacity, the behavior of the beam goes back to how it was without CFRP.

When the beam is considered to be a member, the addition of CFRP increases the member yield capacity of the beam by $11 \%$ as shown in Figure $9 \mathrm{~b}$ which is the same as the section capacity. However, once the CFRP yields and the cracks propagate, localized deformation of CFRP occurs and hence it will accelerate the failure of the beam since the CFRP is quite brittle. Once the CFRP fails, the beam will also fail since the beam cannot carry the same amount of moment when it has the CFRP. Therefore, it should be noted that the CFRP needs to remain elastic in any case to ensure that there will be no brittle failure. It is also shown in Figure $9 \mathrm{~b}$ that creep due to the self-weight generates a residual displacement of approximately $13 \mathrm{~mm}$. Another field measurement was performed after the retrofitting work to measure the effect of the additional CFRP to the deflection of the beam. It was obtained that the additional CFRP did not significantly alter the maximum deflection of the beam as expected. 


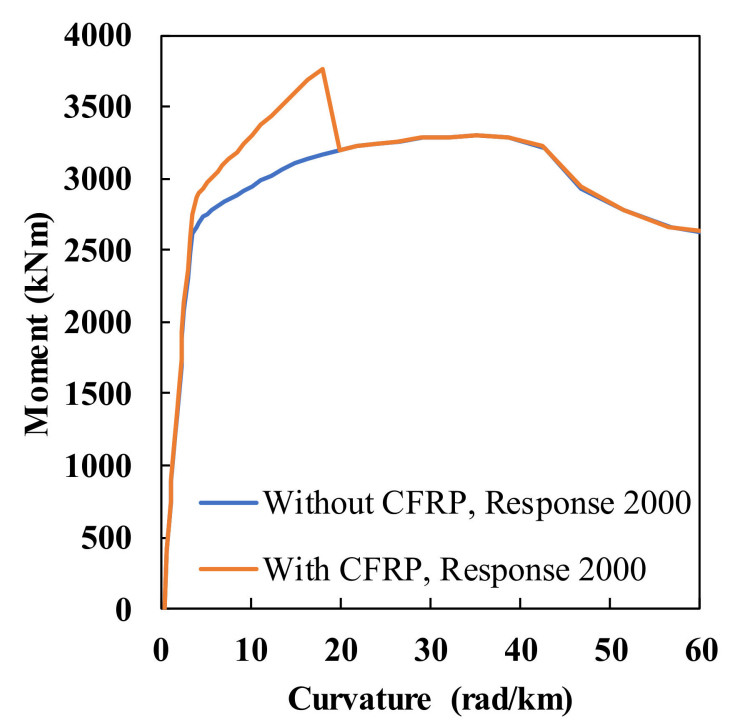

(a)

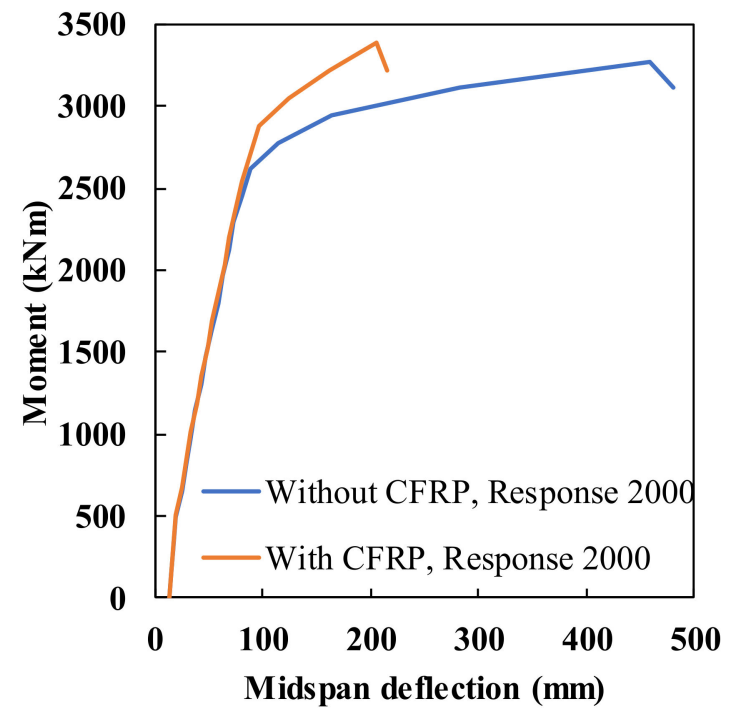

(b)

Figure 9. The moment capacity of individual T-beam: (a) Section capacity; (b) Member capacity.

\section{Parametric Studies}

With a good agreement between the field measurement and the analytical approaches (both Response 2000 and ETABS v13.2.2), parametric studies have been performed to understand the effect of corrosion and overweight truck to the performance of the group of T-beams.

\subsection{The Effect of Corrosion}

The corrosion was considered by reducing a fraction of the rebar diameter. A reduction of $10,20,30$, and $40 \%$ of the nominal diameter of the reinforcing bar was considered in this study. These reductions in the diameter are corresponding to a reduction in the cross-sectional area of 19,36 , $51,64 \%$, respectively. The reduction in the cross-sectional area is assumed to be the corrosion level. Global corrosion, instead of localized corrosion, is assumed in this study to eliminate the complicated process of determining the location of localized corrosion. The maximum load at one wheel of $144 \mathrm{kN}$ suggested by AASHTO [9] and SNI-1727 [27] was used at a various level of corrosion. It should be noted that the moment generated by the wheel load can be reduced by $50 \%$, considering the group effect. Therefore, the moment generated due to the wheel loading $\left(M_{Q}\right)$ at individual beam is approximately equal to $0.5 \times 540=270 \mathrm{kNm}$. Moreover, an impact factor of 1.33 should be considered since the truck is actually moving and may generate higher load due to the roughness of the road surface [9]. The ultimate moment acting on one individual beam can be calculated by using Equation (1), and it is approximately equal to $1340 \mathrm{kNm}$. Using a capacity reduction factor of 0.8 , a minimum ultimate moment capacity of approximately $1675 \mathrm{kNm}$ is required. Considering the high level of importance of the structure, it is preferred that the structure remains in its elastic state.

$$
M^{*}=1.2 M_{G}+1.33(\text { impact factor }) \times 1.6 M_{Q}
$$

All the calculation above assumed that there is only one truck passing one span each time. Considering that there is a possibility that there are two trucks (one truck coming from each direction) passing the same span, the maximum moment generated in Beam 6 will be approximately $310 \mathrm{kNm}$. This is approximately equal to 1.5 times the maximum moment in beam 6 when only one truck is considered. Therefore, new $M_{Q}$ at individual beam considering two trucks is approximately equal to $1.5 \times 270=405 \mathrm{kNm}$. This will yield $M^{*}$ of $1625 \mathrm{kNm}$ and $M_{u}$ of $2030 \mathrm{kNm}$. 
Figure 10 shows that the corrosion reduces both the ultimate moment capacity and the stiffness of the beam after post the cracking moment. Without any corrosion, the yield moment capacity of the retrofitted beam is approximately equal to $2900 \mathrm{kNm}$. Assuming corrosion level of $19 \%$, the yield moment capacity reduces to approximately $2260 \mathrm{kNm}$, which is still higher than the minimum required ultimate moment capacity of $2030 \mathrm{kNm}$ when two trucks are considered. Assuming corrosion level of $36 \%$, the yield moment capacity reduces to approximately $1910 \mathrm{kNm}$, which is lower than the minimum required ultimate moment capacity of $2030 \mathrm{kNm}$ when two trucks are considered. Further increasing the level of corrosion to $51 \%$, the yield moment capacity is further reduced to approximately $1590 \mathrm{kNm}$ which is slightly lower than the minimum required ultimate moment capacity of $1675 \mathrm{kNm}$ when only one truck is considered. Increasing the corrosion level from zero to $50 \%$ will increase the ductility of the beam as reported by Zhu, François [28] even the ductility of individual corroded bar reduces as the corrosion level increases [29]. This is due to the yielding of the reinforcing bars prior to the failure of the CFRP, which leads to the ductile behavior. By further increasing the corrosion level to $64 \%$, it will not only reduce the ultimate capacity, but it also will yield a brittle failure mechanism due to insufficient reinforcing bars to take the load. Almusallam, Al-Gahtani [30] found that the bond strength decreases rapidly when the level of corrosion is $6 \%$, and it became constant when the corrosion level is between $6 \%$ to $80 \%$. Moreover, Bilcik and Holly [31] stated that if minimum transverse reinforcement is provided, the bond strength reduction due to corrosion becomes less since the stirrups will provide the confinement to the main bar. Therefore, it was assumed in this study that the bond strength was not affected due to enough shear reinforcement being provided along the beam.

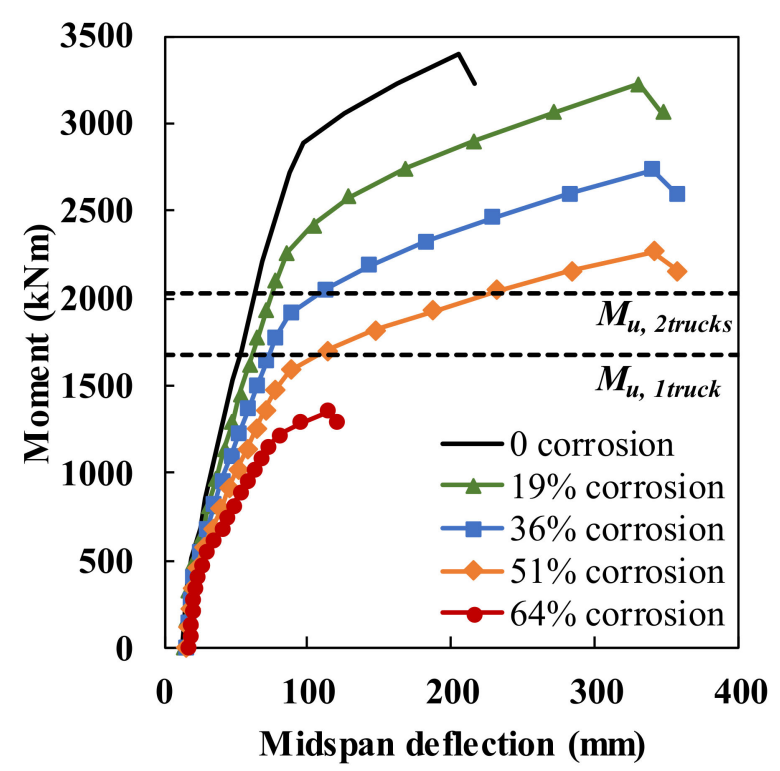

Figure 10. The moment vs midspan deflection of Beam 6 under various corrosion levels.

Figure 11 shows the relationship between the level of corrosion to the yield and ultimate moment capacity of individual T-beam. The yield moment capacity decreases significantly when the level of corrosion is increased from zero to $19 \%$. Further increasing the level of corrosion reduces the yield moment capacity in a linear manner. On the other hand, the ultimate moment capacity of individual T-beam decreases slowly when the level of corrosion increases from zero to $19 \%$. The reduction rate on the ultimate moment capacity increases with the further increase in the level of corrosion. Based on the yield moment capacity of the T-beam as the maximum allowable moment acting on the beam, it is shown that the maximum level of corrosion allowed to occur is approximately $30 \%$ (by linear interpolation). The maximum level is determined considering the worst-case scenario (one truck from each direction passing the same span). Furthermore, if only one truck can pass the bridge each time, the maximum level of corrosion allowed to occur is approximately $47 \%$ (by linear interpolation). It is 
noted that the number of trucks passing through the bridge will affect the maximum moment imposed on the beam (Mu,1truck or Mu,2 trucks). This ultimate moment will limit the allowable corrosion level accordingly.

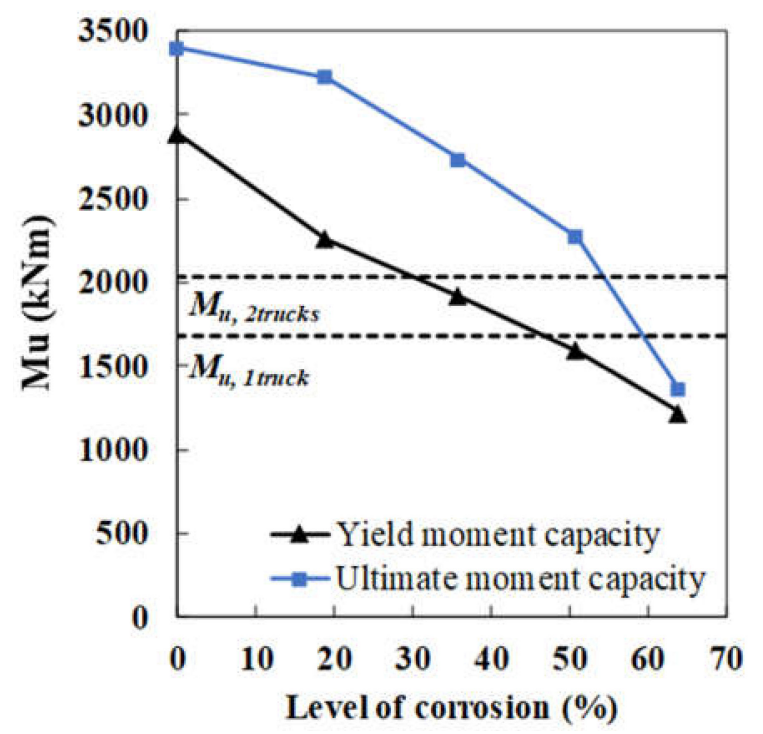

Figure 11. Yield and ultimate moment capacity versus the various level of corrosion.

\subsection{The Effect of Overweight Vehicle}

Figure 10 shows the yield moment capacity of the retrofitted beam without any corrosion is approximately equal to $2900 \mathrm{kNm}$. This value is approximately $42 \%$ higher than the minimum required ultimate moment capacity considering worst-case scenario (two trucks passing the same span) and wheel load of $144 \mathrm{kN}$ suggested from the standard was used [9]. It means that there is an ample capacity to carry even much higher vehicle load. By using Equation (1), the maximum wheel load can be increased to 1.8 of the maximum suggested value from the standard when one truck coming from each direction passing the same span.

Combining the effect of the overweight vehicle and different level of corrosion, the maximum wheel load can be increased to 1.2 times $144 \mathrm{kN}$ when the level of corrosion is $19 \%$. Moreover, the maximum wheel load needs to be reduced when the level of corrosion is $30 \%$ or more. This finding is quite important to decide the service life of the girder.

\section{The Service Life of the T-beam}

There is a time gap of approximately 26 years prior to the repair of the T-beam, which may have caused the rebar to corrode. Therefore, NDT was conducted in 2018 to understand the initiation and propagation time required for the corrosion to take place. The initiation time is the time required for concrete cover to carbonate, which will initiate the corrosion at the rebar. However, the propagation time is the time required for corrosion to propagate and corrode a certain part of the rebar. Ultimately, the total service life of the T-beam is calculated by summing up the initiation time and the propagation time.

The results of the NDT measurement have been reported elsewhere [17]. The NDT tests were meant to be non-destructive and non-intrusive. The equipment, however, has been extensively tested under laboratory and outside environments [14]. In summary, the average electrical resistivity of the concrete cover in the painted web is $374.3 \mathrm{k} \Omega \mathrm{cm}$ which is higher than the unpainted surface at the flange. It means that simply by painting the surface, the electrical resistant of the concrete cover can be increased. Considering the low probability of exceedance of $5 \%$, the electrical resistivity of the painted web is equal to $305.9 \mathrm{k} \Omega \mathrm{cm}$. This value is still much higher than the limit for low corrosion rate of $20 \mathrm{k} \Omega \mathrm{cm}$. This electrical resistivity can be converted to the corrosion rate by using the equations proposed by Andrade and Alonso [32] which is equal to $2.275 \times 10^{-3} \mathrm{~mm} /$ year when 
uniform corrosion is assumed $(\alpha=2)$ and $11.38 \times 10^{-3} \mathrm{~mm} /$ year when localized corrosion at midspan is assumed $(\alpha=10)$ If the level of corrosion of $30 \%$ is used and given that the main rebar at the bottom web has a diameter of $32 \mathrm{~mm}$, the time required for corrosion to propagate is approximately 2390 years and 480 years for uniform and localized corrosion, respectively. If the level of corrosion of $47 \%$ is used for the same rebar diameter, the time required for corrosion to propagate is approximately 3800 years and 760 years for uniform and localized corrosion, respectively.

Moreover, carbonation rate can be estimated by the equation proposed by Kropp and Hilsdorf [33] which requires the value of the coefficient of air permeability $(k T)$ and the depth of the carbonation $\left(D_{c}\right)$. The depth of the carbonation is assumed to be equal to the thickness of the concrete cover. The average $\mathrm{kT}$ value for the painted web is equal to $0.624 \times 10^{-16} \mathrm{~m}^{2}$, which is smaller than the value for the unpainted flange. Again, it shows that the painted surface can provide a protection for the concrete from the carbonation. The average $\mathrm{kT}$ value obtained for the painted web corresponds to an initiation time of 890 years.

The service life of the T-beam can be estimated by considering the different level of corrosion and the weight of the vehicle. During the normal condition, i.e., maximum loading is as per the suggested value in the standard, the total service life of the T-beam can be estimated up to the level of corrosion of $30 \%$. Therefore, the total service life is ranging from 1370 years for localized corrosion and 3280 for uniform corrosion. It should be noted that this estimation assumes that there are no cracks in the concrete. Once a crack occurs, as is the case in the existing bridges, the thickness of the concrete cover decreases and hence will reduce the initiation and propagation time of the corrosion that ultimately will reduce the total service life of the beam.

For instance, when the crack has reached the rebar, the initiation time should be assumed to be zero. Hence, the propagation time required to achieve a localized corrosion level of $30 \%$ is 480 years. Please note that the degree of corrosion may be limited to $19 \%$ if there is an increase in the weight of the truck by $20 \%$. Therefore, the propagation time required to achieve a localized corrosion level of $19 \%$ is 280 years. It means that the stakeholders such as asset owners and port authorities must regularly inspect the bridge to ensure that there is no crack in the beam due to the overweight of the vehicle, earthquake, or differential displacement of the foundation. The interval of the inspection is typically three years. Moreover, the performance of the bonding material between the carbon fiber and the concrete should also be checked periodically.

Considering only creep and shrinkage according to AASHTO [9], the total service life of the beam can be estimated by setting the maximum deflection at service to be span on 480 and changing the duration of the sustained loading. It was obtained that by further increasing the duration of the sustained loading to be larger than 26 years (it was tried up to 3000 years), the effect of creep and shrinkage seems to be similar to that at 26 years. It means that serviceability limit state (SLS) will be satisfied during the total service life of the structure and hence, ultimate limit state (ULS) will govern the design. This information is very useful for the stakeholder to make a strategic decision to maintain the performance of the bridge over its service life.

\section{Conclusions}

A high importance precast RC T-beam located in Terminal Peti Kemas (TPS) Surabaya was assessed 26 years after construction and then 34 years after construction to understand its long-term performance. At 26 years, the bridge was retrofitted by grouting the cracks, painting the web, and adding two strips of CFRP. The deflection of the beam prior to and after the retrofitting work was measured. At 34 years, the bridge was assessed using NDT equipment to understand the resistance of this beam towards carbonation and chloride-induced corrosion.

FEA was performed to understand the effect of the creep and shrinkage due to the self-weight of the structure to the deflection of the beam. The results obtained from the fEA and the field work were in good agreement. Finite element analysis (FEA) was also performed to incorporate the group effects of the bridge since each span of the bridge consists of 9 T-beams connected each other with a concrete slab 
on top of the beam. Again, good agreement was obtained between the measured deflections (due to both self-weight and the wheel load) from the field observations and the FEA was also obtained.

A further parametric study was performed by using the model used previously by changing several important parameters, such as the effect of additional CFRP, the effect of different level of corrosion, and the effect of the different magnitude of wheel load. The results obtained from the NDT were used in conjunction with the analytical result to obtain the total service life of the structure due to the ultimate capacity of the girder. Moreover, the total service life of the structure due to the service load was also determined.

The main findings obtained in the parametric study and total service load determination were summarized as follows:

1. The addition of two strips of CFRP (each has a dimension of $100 \times 1.2 \mathrm{~mm}$ ) increases the member yield capacity of the beam by $11 \%$. Once the CFRP yields and the cracks propagate, localized deformation of CFRP occurs, and hence it will accelerate the failure of the CFRP since the CFRP is quite brittle. Once the CFRP fails, the beam will also fail since the beam cannot carry the same amount of moment when it has the CFRP.

2. The group effect can reduce the maximum moment occurred in individual T-beam due to the wheel load from one truck by approximately 50\%. By having two trucks (one truck from each direction), the maximum moment occurred in individual T-beam will be increased by 1.5 compared to the case with only one truck. Therefore, if individual T-beam is analyzed instead of a group of beams, then the maximum moment due to two trucks will be approximately equal to $0.5 \times 1.5 \times M_{Q}=0.75 M_{Q}$; where $M_{Q}$ is the maximum moment due to one wheel load at midspan of individual T-beam.

3. Corrosion reduces both the ultimate moment capacity and the stiffness of the beam after post the cracking moment. It is shown that the maximum level of corrosion that is allowed to occur is approximately $30 \%$ (by linear interpolation) considering the worst-case scenario (one truck from each direction passing the same span) and given the sufficient shear reinforcement is provided.

4. The effect of creep and shrinkage will not increase as the duration of the sustained load increases from 26 years to 3000 years. Therefore, if creep effect is constant throughout the entire service life of the structure is reasonable. In this study, the creep increases the maximum deflection due to the self-weight to 2.3 times the immediate deflection due to the self-weight.

5. Considering the worst-case scenario (one truck from each direction), the maximum wheel load can be increased to 1.8 of the maximum suggested value from the standard $(144 \mathrm{kN})$ when there is no corrosion. Furthermore, the maximum wheel load can be increased to 1.2 times $144 \mathrm{kN}$ when the level of corrosion is $19 \%$.

6. The study reports on the service life of the structure. Assuming maximum wheel load on an uncracked beam and 30\% corrosion level, the service life of the structure is estimated to be approximately 3280 years and 1370 years for uniform and localized corrosion, respectively.

7. The findings of the study highlight the importance of structural assessment based on the combination of condition assessment, structural analysis, and consideration of material properties as a strategy to improve the service life of the structure.

Author Contributions: Conceptualization: M.S., E.L.; methodology: Y.O. and E.L.; software: Y.O.; validation and investigation: Y.O., E.L.,M.S., G.K.; writing-original draft preparation: Y.O.; writing-review and editing: M.S. and E.L.; visualization: Y.O. and G.K.; supervision: E.L. and M.S. G.K.; project administration: C.D., E.L. and M.S.; funding acquisition: E.L., M.S. and C.D. All authors have read and agreed to the published version of the manuscript.

Funding: This research was funded by Australian Indonesian Centre (AIC): Project Title: Structural Performance of Critical Infrastructures in Port Development, Infrastructure Cluster Strategic Projects, Strategic Research Project 2 (SRP2), 2016. 
Acknowledgments: The authors would like to thank Suluh and crew from Terminal Peti Kemas Surabaya for providing the data as well as allowing the authors to perform the non-destructive test (NDT) at the bridge and Hera Widiastuti from Institute Technology of Sepuluh November (ITS) for the continuous support throughout the project.

Conflicts of Interest: The authors declare no conflict of interest.

\section{References}

1. Alisjahbana, A. Effective public spending: The case of infrastructure. In Proceedings of the 2012 OECD Global Forum on Development, Paris, France, 29 February 2012.

2. Marga, B. Strategical Plan of Ministry of General Work and Public Housing in Developing and Improving the Road (In Indonesian); Directorate General Bina Marga, Ministry of General Work and Public Housing: Jakarta, Indonesia, 2016.

3. Erdianto, K. The Cause of the 17 Million IDR Bridge Collapse in South Kalimantan (in Indonesian). Available online: https://regional.kompas.com/read/2017/08/18/17470711/ini-penyebab-ambruknya-jembatan-rp-17 -miliar-di-kalimantan-selatan- (accessed on 20 June 2018).

4. Fachri, F. Tuban Bridge is Allegedly Problematic Since 2015 (in Indonesian). Available online: http://nasional.republika.co.id/berita/nasional/daerah/18/04/18/p7deme377-jembatan-tuban-didu ga-sudah-terdeteksi-bermasalah (accessed on 20 June 2018).

5. Rusyanto, E. Ten Bridges Collapse in Indonesia (in Indonesian). Available online: https://edorusyanto.word press.com/2016/10/18/10-jembatan-runtuh-paling-menghebohkan-di-indonesia/.

6. Kaphle, M.; Tan, A.C.; Kim, E.; Thambiratnam, D. Application of acoustic emission technology in monitoring structural integrity of bridges. In Proceedings of the 4th World Congress on Engineering Asset Management, Athens, Greece, 28-30 September 2009; Springer: London, UK, 2010.

7. Meyers, B.L.; Slate, F.; George, W. Relationship between time-dependent deformation and microcracking of plain concrete. J. Am. Concr. Inst. 1969, 66, 60-68.

8. Ngab, A.S.; Slate, F.O.; Arthur, H.N. Microcracking and time-dependent strains in high strength concrete. J. Am. Concr. Inst. 1981, 78, 262-268.

9. AASHTO. LRFD Bridge Design Specifications; American Association of State Highway and Transportation Officials: Washington, DC, USA, 2012.

10. Omar, M.; Loukili, A.; Pijaudier-Cabot, G.; Le Pape, Y. Creep Damage Coupled Effects: Experimental Investigation on Bending Beams with Various Sizes. J. Mater. Civ. Eng. 2009, 21, 65-72. [CrossRef]

11. Chang, S.E. Transportation Performance, Disaster Vulnerability, and Long-Term Effects of Earthquakes. In Proceedings of the Second Euro Conference on Global Change and Catastrophe Risk Management, Laxenburg, Austria, 6-9 July 2000.

12. Eberhard, M.O.; Baldridge, S.; Marshall, J.; Mooney, W.; Rix, G.J. The MW 7.0 Haiti Earthquake of January 12, 2010; USGS/EERI Advance Reconnaissance Team Report; US Geological Survey: Menlo Park, CA, USA, 2010; p. 58.

13. Mondal, G.; Rai, D.C. Performance of harbour structures in Andaman Islands during 2004 Sumatra earthquake. Eng. Struct. 2008, 30, 174-182. [CrossRef]

14. Sofi, M.; Oktavianus, Y.; Lumantarna, E.; Rajabifard, A.; Duffield, C.; Mendis, P. Condition assessment of concrete by hybrid non-destructive tests. J. Civ. Struct. Health Monit. 2019, 9, 339-351. [CrossRef]

15. AS 3600. Concrete Structures; Standards Australia Limited: Sydney, Australia, 2018.

16. SNI 03-2847. Procedures for Calculating Reinforced Concrete Structures for Buildings (in Indonesian); Standard Nasional Indonesia: Bandung, Indonesia, 2002.

17. Oktavianus, Y.; Sofi, M.; Lumantarna, E.; Maizuar, M.; Mendis, P.; Duffield, C.; Rajabifard, A.; Widyastuti, H. Use of non-destructive methods: Case studies of marine port and bridges structures in Surabaya. Electron. J. Struct. Eng. 2018, 18, 13-22.

18. Lam, N.; Wilson, J.; Lumantarna, E. Force-deformation behaviour modelling of cracked reinforced concrete by EXCEL spreadsheets. Comput. Concr. 2011, 8, 43-57. [CrossRef]

19. Menegon, S.J.; Wilson, J.L.; Lam, N.T.; Gad, E.F. Development of Simple and Transparent Non-Linear Analysis Methods for RC Walls. In Proceedings of the Australian Earthquake Engineering Society 2018 Conference, Perth, WA, USA, 16-18 November 2018. 
20. TPS. Research on the Repair Work of the Trestle in Terminal Peti Kemas Surabaya (Indonesian Version); PT. TPS: Surabaya, Indonesia, 2013.

21. BGA. Strengthening Calculation for the Beam of the Trestle in Terminal Peti Kemas Surabaya (In Indonesian); Benjamin, Gideon \& Associates: Surabaya, Indonesia, 2010.

22. Bentz, E.C. Sectional Analysis of Reinforced Concrete Members; University of Toronto: Toronto, ON, Canada, 2000.

23. Popovics, S. A numerical approach to the complete stress-strain curve of concrete. Cem. Concr. Res. 1973, 3, 583-599. [CrossRef]

24. Collins, M.P.; Porasz, A. Shear strength for high strength concrete. Bull. D'Inf. 1989, 193, 77-83.

25. Vecchio, F.J.; Collins, M.P. The modified compression-field theory for reinforced concrete elements subjected to shear. J. Am. Concr. Inst. 1986, 83, 219-231.

26. CSI ETABS 2013 V13.2.2; Computers \& Structures, Inc.: Berkeley, CA, USA, 2014.

27. SNI-1727. Minimum Design Loads for Buildings and Other Structures (in Indonesian); National Standardization Agency of Indonesia: Jakarta, Indonesia, 2013.

28. Zhu, W.; François, R.; Coronelli, D.; Cleland, D. Effect of corrosion of reinforcement on the mechanical behaviour of highly corroded RC beams. Eng. Struct. 2013, 56, 544-554. [CrossRef]

29. Almusallam, A.A. Effect of degree of corrosion on the properties of reinforcing steel bars. Constr. Build. Mater. 2001, 15, 361-368. [CrossRef]

30. Almusallam, A.A.; Al-Gahtani, A.S.; Aziz, A.R. Rasheeduzzafar Effect of reinforcement corrosion on bond strength. Constr. Build. Mater. 1996, 10, 123-129. [CrossRef]

31. Bilcik, J.; Holly, I. Effect of Reinforcement Corrosion on Bond Behaviour. Procedia Eng. 2013, 65, $248-253$. [CrossRef]

32. Andrade, C.; Alonso, C. Test methods for on-site corrosion rate measurement of steel reinforcement in concrete by means of the polarisation resistance method. Mater. Struct. 2004, 37, 623-643. [CrossRef]

33. Kropp, J.; Hilsdorf, H.K. Performance Criteria for concrete Durability—RILEM Report 12; CRC Press: Boca Raton, FL, USA, 1995.

(C) 2020 by the authors. Licensee MDPI, Basel, Switzerland. This article is an open access article distributed under the terms and conditions of the Creative Commons Attribution (CC BY) license (http://creativecommons.org/licenses/by/4.0/). 